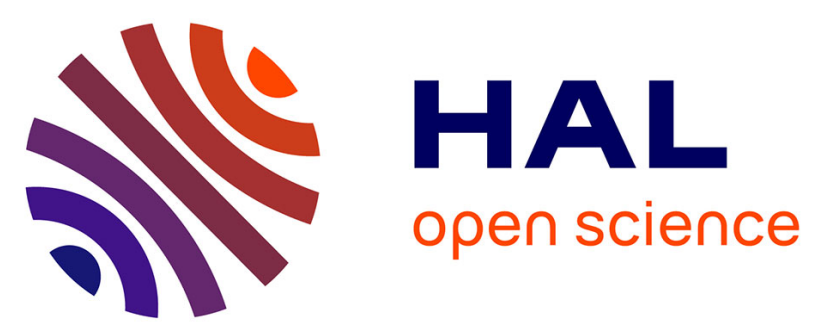

\title{
Unimolecular reactivity of the [urea-Sr] $2+$ complex, a metastable dication in the gas phase. An experimental and theoretical perspective
}

\author{
Ane Eizaguirre, Otilia Mó, Manuel Yáñez, Jeanine Tortajada, Jean-Yves
} Salpin

\section{To cite this version:}

Ane Eizaguirre, Otilia Mó, Manuel Yáñez, Jeanine Tortajada, Jean-Yves Salpin. Unimolecular reactivity of the [urea-Sr] $2+$ complex, a metastable dication in the gas phase. An experimental and theoretical perspective. Journal of Physical Chemistry B, 2013, 117 (7), pp.2088-2095. 10.1021/jp312466t . hal-00912477

\section{HAL Id: hal-00912477 \\ https://hal.science/hal-00912477}

Submitted on 5 Oct 2018

HAL is a multi-disciplinary open access archive for the deposit and dissemination of scientific research documents, whether they are published or not. The documents may come from teaching and research institutions in France or abroad, or from public or private research centers.
L'archive ouverte pluridisciplinaire HAL, est destinée au dépôt et à la diffusion de documents scientifiques de niveau recherche, publiés ou non, émanant des établissements d'enseignement et de recherche français ou étrangers, des laboratoires publics ou privés. 


\title{
Unimolecular Reactivity of the $\left[\right.$ Urea-Sr] ${ }^{2+}$ Complex, a Metastable Dication in the
}

\section{Gas Phase. An Experimental and Theoretical Perspective}

Ane Eizaguirre ${ }^{1}$, Otília Mó*1, Manuel Yáñez ${ }^{1}$, Jeanine Tortajada ${ }^{2,3}$ and Jean-Yves Salpin $*^{2,3}$

${ }^{1}$ Departamento de Química, Módulo 13, Facultad de Ciencias. Universidad Autónoma de Madrid. Campus de Excelencia UAM-CSIC. Cantoblanco. 28049 - Madrid. Spain

${ }^{2}$ Université d'Evry Val d'Essonne - Laboratoire Analyse et Modélisation pour la Biologie et l'Environnement (LAMBE) - Bâtiment Maupertuis - Boulevard François Mitterrand, 91025 Evry, France

${ }^{3}$ CNRS - UMR 8587

\begin{abstract}
The interactions between urea and $\mathrm{Sr}^{2+}$ in the gas phase have been investigated by combining electrospray ionization/mass spectrometry techniques and density functional and high-level $a b$ initio molecular orbital calculations. Our theoretical survey indicates that $[\operatorname{Sr}(\text { urea })]^{2+}$ adducts are thermodynamically stable with respect to direct Coulomb explosions. However, after isomerization, some of the local minima of the PES are thermodynamically unstable with respect to the formation of $\mathrm{NH}_{4}{ }^{+}$, but kinetically metastable. The loss of neutral fragments with the concomitant generation of lighter doubly-charged fragment ions, namely $\left[\left(\mathrm{H}_{3} \mathrm{~N}\right) \mathrm{Sr}\right]^{2+}$ and $[(\mathrm{HNCO})] \mathrm{Sr}^{2+}$, compete with the aforementioned Coulomb explosion processes yielding $\mathrm{NH}_{4}{ }^{+}+[(\mathrm{NCO}) \mathrm{Sr}]^{+}$and $\left[\left(\mathrm{H}_{2} \mathrm{~N}\right) \mathrm{Sr}\right]^{+}+\left[\mathrm{H}_{2} \mathrm{NCO}\right]^{+}$, although the former processes dominate. Hence, both singlyand doubly-charged species are detected as dissociation products. Quite importantly, the observed eliminations of $\mathrm{NH}_{3}$ or $\mathrm{HNCO}$, lead to the formation of new doubly-charged species, which turn out to be thermodynamically stable.
\end{abstract}

Keywords: Gas-phase reactions; urea; $\mathrm{Sr}^{2+}$; electrospray mass spectrometry; molecular orbital calculations; Coulomb explosions 


\section{Introduction}

Ion-molecule reactions in the gas phase opened a new perspective in modern chemistry because the absence of interactions with the media resulted in reactivity patterns very different in most cases to those observed in solution. ${ }^{1}$ This actually gave rise to a new term, intrinsic reactivity, ${ }^{2}$ to describe the reactivity that a given compound exhibits per $s e$. Thus, not surprisingly, the number of experimental studies on gas-phase ionmolecule reactions increased enormously along the years. ${ }^{3}$ Nevertheless, a great majority of these studies were focused on singly-charged species, ${ }^{2,4-11}$ because many doubly or multiply charged species turned out to be unstable ${ }^{12}$ in the absence of the interaction with the solvent or with the crystal environment, and as a consequence until the nineties and the advent of electrospray techniques ${ }^{13-15}$, multiply charged species in the gas phase were considered an oddity. The main consequence is that during many years our knowledge on reactivity patterns of ions in the gas phase was essentially restricted to monocations. Even, some controversy could be found in the literature concerning the existence of some molecular dications in the gas phase. ${ }^{16-19}$ The stability of doubly or multiply charged species is particularly critical when they are the result of the association of a doubly (or multiply) charged transition metal ion, $\mathrm{M}^{2+}$, to a neutral organic compound, $\mathrm{B}$, because in general, the recombination energy of $\mathrm{M}^{2+}$ is much larger than the ionization energy of $\mathrm{B}$. The immediate consequence is that the association of the metal ion to the base $\mathrm{B}$ results in an oxidation of the latter, ${ }^{20-23}$ which is normally followed by a deprotonation of the radical cation formed within the metalion complex. ${ }^{22,24}$ Hence, in general, it is not possible to detect the $[\mathrm{MB}]^{2+}$ species, and only $[\mathrm{M}(\mathrm{B}-\mathrm{H})]^{+}$singly-charged species are detected. The situation changes dramatically 
when dealing with alkaline-earth metal dications, such as $\mathrm{Ca}^{2+}$ or $\mathrm{Sr}^{2+}$, because their recombination energies are much lower than those of transition metal dications and therefore they are not able to oxidize the base, so the $[\mathrm{CaB}]^{2+}$ or $[\mathrm{SrB}]^{2+}$ species are stable and detectable in the gas phase. ${ }^{25-40}$

Interestingly however, the reactivity of these doubly charged molecular ions brings new questions up, because in principle two different kinds of fragmentations are possible, those in which the system loses a neutral fragment producing a new and lighter doublycharged molecular ion, or those in which the system undergoes a Coulomb explosion yielding two singly charged products. Which of these two kinds of processes dominate is an important question, and the observed behavior clearly depends on the base in question. For instance, whereas it has been found that in $[\mathrm{Ca}(\text { urea })]^{2+}$ dissociation process, both kinds of mechanisms compete, ${ }^{30,41}[\mathrm{Ca}(\text { glycine })]^{2+}$ gas-phase unimolecular dissociation is completely dominated by the Coulomb explosions. ${ }^{33}$ The aim of this paper is to investigate whether this behavior may change significantly when using heavier metal ions. For this purpose we will present in what follows a combined experimental and theoretical investigation of the gas-phase interactions of urea with $\mathrm{Sr}^{2+}$. We have chosen these reactants because urea, together with other small compounds such as formamide, constitutes a good model to understand the reactivity of large biochemical compounds such as the nucleobases which include the same key functional groups. On the other hand, Sr has also a significant relevance in the treatment of osteoporosis, ${ }^{42,43}$ in spite of being a trace metal in the physiological media.

\section{Experimental section}

Electrospray MS and MS/MS mass spectra were recorded on a QSTAR PULSAR i (AB Sciex) hybrid instrument (QqTOF) fitted with an ionspray source. Equimolar aqueous 
mixtures of strontium chloride and urea $\left(10^{-4} \mathrm{~mol} \mathrm{~L}^{-1}\right)$ were introduced into the source using direct infusion with a syringe pump at a flow rate of $4 \mu \mathrm{l} / \mathrm{min}$. Ionization of the sample was achieved by applying a voltage of $4.7-5.0 \mathrm{kV}$ to the sprayer probe and by the use of a nebulizing gas (GAS1, air) surrounding the sprayer probe. The operating pressure of GAS1 was adjusted to 1.4 bar by means of an electronic board (pressure sensors) as a fraction of the air inlet pressure. The declustering potential DP (also referred to as "cone voltage" in other devices), defined as the difference in potential between the orifice plate and the skimmer (grounded), ranged from 20 to $120 \mathrm{~V}$. The operating pressure of the curtain gas $\left(\mathrm{N}_{2}\right)$, which prevents air or solvent from entering the analyzer region, was similarly adjusted to 0.7 bar. Ion transmission and consequently sensitivity was improved thanks to collisional focusing, by introducing continuously nitrogen in both Q0 (ion guide preceding the quadrupole Q1 and located just after the skimmer) and Q2 (collision cell) sectors.

For MS/MS spectra, complexes of interest were mass selected using Q1, and allowed to collide with nitrogen as collision gas in the second quadrupole (Q2), the resulting product ions being analyzed by the time-of-flight (TOF) after orthogonal injection. MS/MS spectra were systematically recorded at various collision energies ranging from $8 \mathrm{eV}$ to $20 \mathrm{eV}$ in the laboratory frame (the collision energy is given by the difference between the potentials of Q0 and Q2). This corresponds to center-of-mass collision energies $\left(\mathrm{E}_{\mathrm{CM}}\right)$ ranging from 2.55 to $6.36 \mathrm{eV}$. The CAD parameter, which roughly controls the amount of $\mathrm{N}_{2}$ introduced into $\mathrm{Q} 2$, was set to its minimum value in order to limit multiple ion-molecule collisions. Setting this parameter to 1 during MS/MS experiments resulted in pressure values of c.a. $210^{-5}$ Torr as measured by the ion gauge located at vicinity but outside the collision cell. However, It has been reported ${ }^{44}$ that the pressure inside the collision cell is in fact in the order of $10 \mathrm{mTorr}$. At this pressure and 
given the dimension of the LINAC collision cell (about 22 centimeters long), one can find that the mean free path for a $\mathrm{N}_{2}$ molecule is about $5 \mathrm{~mm}$. So, at this pressure not only $\mathrm{N}_{2}$ molecule but also complexes of interest (which have higher collision crosssections) may undergo tens of collisions along their path through Q2. Note that this estimate is a lower limit since $\mathrm{N}_{2}$ also enters Q0 and Q1 for collisional focusing. Consequently, even with the minimum amount of $\mathrm{N}_{2}$ introduced inside the collision cell, we are certainly under a multiple collision regime.

All experiments were performed in $100 \%$ water purified with a Milli-Q water purification system. Both urea and strontium chloride were purchased from Aldrich (St Quentin-Fallavier, France) and were used without further purification. Unless otherwise noted, mass to charge ratios mentioned throughout this paper refer to as peaks including the most abundant strontium isotope $\left({ }^{88} \mathrm{Sr}\right)$.

\section{Computational Details}

Density functional theory approaches are particularly well suited for the treatment of molecular cations and dications, providing a good compromise between accuracy and computational costs. In a previous theoretical assessment we have found ${ }^{45}$ that, among the different functionals nowadays available, G96LYP, ${ }^{46,47}$ as implemented in the Gaussian 09 suite of programs, was the one which exhibited a better performance when compared with high-level $\operatorname{CCSD}(\mathrm{T})$ ab initio calculations, for the treatment of $\mathrm{Sr}^{2+}$ complexes. Hence, this will be the method used in the present study. For geometry optimizations this DFT approach was used together with a mixed basis set, which corresponds to a 6-31+G(d,p) expansion for $\mathrm{C}, \mathrm{O}, \mathrm{N}$ and $\mathrm{H}$ atoms, and an improved LAN2DZ basis set for the $\mathrm{Sr}^{2+}$ cation, proposed in ref. 45, and which includes diffuse and $d$ polarization functions on this center. Final energies were obtained in single-point 
calculations carried out on the previously optimized structures, but using a much larger basis set expansion, which includes a $6-311+\mathrm{G}(3 \mathrm{df}, 2 \mathrm{p})$ basis set for $\mathrm{C}, \mathrm{N}, \mathrm{O}$ and $\mathrm{H}$ atoms, together with an extended LAN2DZ proposed for $\mathrm{Sr}^{2+}$ cation ${ }^{45}$, which adds to the standard LAN2DZ a set of diffuse functions, three sets of $d$ and one set of $f$ polarization functions. In order to classify stationary points of the potential energy surface either as local minima or transition states (TS) and to estimate the zero-point vibrational energy (ZPVE) corrections for all the species investigated, the harmonic vibrational frequencies were computed at the same level used for geometry optimization. It should be taken into account that the transition states associated with Coulomb explosions formally have a multireference character, since they arise from the crossing of a covalent and an ionic potential energy curves. It has been shown however in the literature that, in spite of this formal multireference character, these transition states are well described by $\operatorname{CCSD}(\mathrm{T})$ single reference methods. ${ }^{19,48-51}$ In order to verify this in the case here, we have recalculated the activation barriers associated with the Coulomb explosions by means of $\operatorname{CCSD}(\mathrm{T})$ calculations using the larger basis set described above. As we will discuss in forthcoming sections no significant changes on the height of the barriers have been found.

One of the signatures of the interactions between doubly-charged metal ions and neutral bases is the significant perturbation that the former cause on the electron density of the latter. To analyze these electron density rearrangements and their effect on the bonding characteristics of the base we have employed the atoms in molecules (AIM) theory. ${ }^{52,53}$ Since this approach is based on a topological analysis of the electron density, it provides immediately a clear picture of the aforementioned rearrangements, which can be easily detected through the values of the electron density at the so-called bond critical points (BCPs), which correspond to stationary points of the electron density in 
which this property is minimum in one direction and maximum in the other two. The ensemble of BCPs, local maxima of the electron density and the lines connecting them, usually named bond paths, defines the molecular graph of the system which provides a clear picture of the network of bonds that stabilize the system. These calculations were performed with the AIMAll series of programs. ${ }^{54}$

The AIM description can be nicely complemented with the one obtained using the Electron Localization Function (ELF) theory, proposed by Becke and Edgecombe. ${ }^{55}$ This approach, leads to a description of the valence shell of a molecule in terms of regions occupied by electron pairs, usually named basins. In general ELF partitions the molecular space into two types of basins: polysynaptic basins (generally disynaptic), with the participation of two (or more) atomic valence shells and monosynaptic ones, which correspond to electron lone-pairs or core electrons. ${ }^{56}$ It is worth mentioning that this method provides useful information about the nature of the bonding in challenging cases in which other approaches fail to give an unambiguous bonding picture ${ }^{57}$ ELF calculations were carried out with the TopMod suite of programs. ${ }^{58}$

\section{Results and Discussion}

\section{Experimental spectra}

Figure 1a shows a typical electrospray spectrum obtained with an equimolar aqueous mixture of strontium chloride and urea $\left(10^{-4} \mathrm{~mol} \mathrm{~L}^{-1}\right)$. This spectrum is remarkably simple. First, chlorine-containing species are not detected, regardless of the interface conditions used. Strontium-containing ions can be easily identified because of the specific isotopic distribution of this metal, resulting in characteristic triplets. Several types of ions are observed. Like for previous studies involving either $\mathrm{Ca}^{2+}$ $30,33,36,38,59,60$ or $^{2+} \mathrm{Sr}^{29}$, adopting a low cone voltage ( $\mathrm{DP}=0-20 \mathrm{~V}$ ) results in the abundant 
production of doubly-charged species. At $\mathrm{DP}=20 \mathrm{~V}$, the mass spectrum is characterized by prominent hydrated strontium ions $\left(\left[\mathrm{Sr}\left(\mathrm{H}_{2} \mathrm{O}\right)_{m}\right]^{2+} ; m=1-3\right)$ detected at $m / z 52.95$, 61.96 and 70.97, respectively. Their abundance quickly drops off has one increases the declustering potential (DP). Higher DP values indeed promotes their dissociation within the interface region, leading to the formation of abundant strontium hydroxide $[\mathrm{SrOH}]^{+}$ $(\mathrm{m} / \mathrm{z}$ 104.90). Interaction between urea and strontium ion gives rise almost exclusively to doubly-charged complexes of the type $\left(\left[\operatorname{Sr}(\text { urea })_{n}\right]^{2+} .(\mathrm{n}=1-3)\right.$, observed at $m / z 73.96$, 103.98 and 133.99. Another dication, namely $\left[\mathrm{Sr}(\text { urea }) \cdot \mathrm{H}_{2} \mathrm{O}\right]^{2+}(\mathrm{m} / \mathrm{z}$ 82.97) is also present, albeit in weak abundance. The singly charged complex $[\operatorname{Sr}(\text { urea })-H]^{+}$is detected in significant abundance only for DP values greater than $60 \mathrm{~V}$, and arises from the $\left(\left[\operatorname{Sr}(\text { urea })_{n}\right]^{2+}\right.$ ions $(n=2,3)$ by an interligand proton transfer followed by charge separation driven by Coulomb explosion, as confirmed by the MS/MS spectrum of the $m / z 103.99$ ion (not shown). 

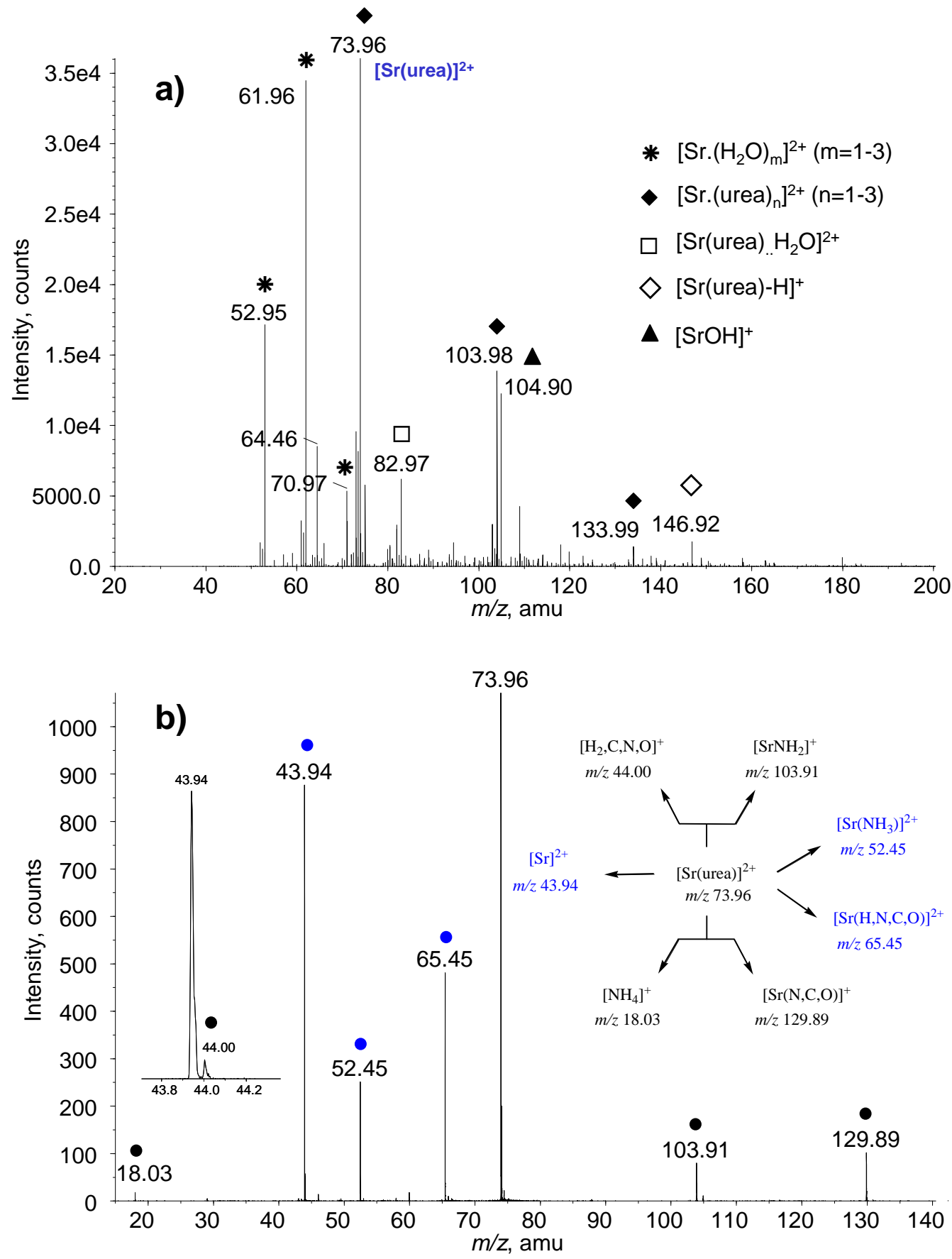

Figure 1: a) Positive-ion electrospray spectrum of an equimolar aqueous $\mathrm{SrCl}_{2}$ /urea (10${ }^{4} \mathrm{~mol} \mathrm{~L}^{-1}$ ) mixture, recorded with a declustering potential of $40 \mathrm{~V}$; b) Low-energy CID spectrum of the $\left[\mathrm{Sr}(\text { urea) }]^{2+}\right.$ complex recorded with a collision energy of $13 \mathrm{eV}$ (laboratory frame) See text for details

Finally, due to the presence of acetonitrile in trace amounts, a $\left[\mathrm{Sr}\left(\mathrm{CH}_{3} \mathrm{CN}\right)\right]^{2+}$ complex is also detected at $\mathrm{m} / \mathrm{z}$ 64.46. Such doubly-charged complexes have been already observed with alkaline-earth dications such as $\mathrm{Ca}^{2+}$ or $\mathrm{Sr}^{2+}$. 61,62 
We will now focus our attention on the MS/MS spectra of the $\left[\operatorname{Sr}(\text { urea) }]^{2+}\right.$ complex. The DP parameter was set to $40 \mathrm{~V}$ to record these MS/MS spectra, the CAD parameter being set to its minimum value (1). Different DP values were initially considered but spectra were found not to depend on this parameter. A typical CID spectrum recorded for the $[\operatorname{Sr}(\text { urea })]^{2+}$ species is given in Figure 1 b. As generally observed for such doublycharged ions, the $[\mathrm{Sr}(\text { urea })]^{2+}$ complex first dissociates according to neutral losses, thereby generating new dications, presently detected at $\mathrm{m} / \mathrm{z} 65.45,52.45$ and 43.94 . These three species are associated with elimination of ammonia, a $[\mathrm{H}, \mathrm{N}, \mathrm{C}, \mathrm{O}]$ moiety and intact urea, respectively. The second type of fragmentation characteristic of the unimolecular reactivity of $[\mathrm{M}(\mathrm{L})]^{2+}$ complexes $(\mathrm{M}=$ metal; $\mathrm{L}=$ ligand), corresponds to charge separation processes leading to singly-charged ions. Two of these processes are presently observed, resulting in the formation of $m / z 18.03 / 129.89$ and $m / z$ 44.0/103.91 pairs, that may be attributed to $\left[\mathrm{NH}_{4}\right]^{+} /[\mathrm{Sr}(\mathrm{N}, \mathrm{C}, \mathrm{O})]^{+}$and $\left[\mathrm{H}_{2}, \mathrm{~N}, \mathrm{C}, \mathrm{O}\right]^{+} /\left[\mathrm{Sr}\left(\mathrm{NH}_{2}\right)\right]^{+}$, respectively. Singly charged fragment ions are found less abundant than the dications arising from neutral losses.

As one could expect, this MS/MS spectrum is therefore practically identical to the CID spectrum recorded for $[\mathrm{Ca}(\text { urea })]^{2+30}$, since both ions generated and neutrals eliminated are strictly similar. One noticeable difference is the particularly high abundance of the $\mathrm{Sr}^{2+}$ ion $(\mathrm{m} / z$ 43.94). As usually observed, the lightest ions arising from charge separation processes are less intense than the heaviest ones. 30,33,38,59,63 This phenomenon has been interpreted in terms of different radial ion energies, with the lighter ions generated by the Coulomb explosion gaining most of the radial energy and therefore having a much higher velocity than the relatively high mass ions. This can result in an unstable ion trajectory within the instrument and explains why lighter ions are detected in the MS/MS spectrum with smaller abundance. 
It is worth noting that both elimination of ammonia and of a $43 \mathrm{Da}$ fragment were also encountered for the singly-charged $[\mathrm{Sr}(\text { urea })-\mathrm{H}]^{+}$complex, and for $[\mathrm{M}(\text { urea })]^{+}$ complexes formed with $\mathrm{Cu}^{+64,65}$ and $\mathrm{Ni}^{+}{ }^{66}$ ions. However, unlike the corresponding situations for $\mathrm{Cu}^{+}$or $\mathrm{Ni}^{+}$, the loss of water, (which has been attributed to a partial collision-induced isomerization of $[\mathrm{M}(\text { urea })]^{+}$species in the cone region prior to mass selection ${ }^{65,66}$ ), and elimination of carbon monoxide, are not observed. To complete this experimental survey, it is worth adding that the CID spectra of $[\operatorname{Sr}(\text { urea })]^{2+}$ and $[\mathrm{Sr}(\text { formamide })]^{2+}$ are markedly different since formation of $[\mathrm{SrOH}]^{+},\left[\mathrm{Sr}\left(\mathrm{H}_{2} \mathrm{O}\right)\right]^{2+}$ and $[\mathrm{Sr}(\mathrm{CO})]^{2+}$ associated with the unimolecular dissociation of the latter ${ }^{39}$ are presently not observed with the former.

\section{Structure and relative stability}

The global minimum of the Urea-Sr ${ }^{2+}$ potential energy surface (PES) corresponds to the adduct $\mathbf{1}$ in which the metal dication is attached to the carbonyl oxygen, aligned with the dipole moment of urea (See Figure 2), indicating that similarly to $\mathrm{Ca}^{2+},{ }^{30} \mathrm{Sr}^{2+}$ has also preference to bind to oxygen atoms. $47 \mathrm{~kJ} \mathrm{~mol}^{-1}$ higher in energy lies a second local minimum $\mathbf{2}$, in which one of the amino groups of the base has rotated to favor the interaction of the metal with it and the carbonyl group simultaneously. As we shall see in forthcoming sections, these two structures are connected by a rather low isomerization barrier and they are the origin of the different unimolecular fragmentations of gaseous $[\mathrm{Sr}(\text { urea })]^{2+}$ ions. 


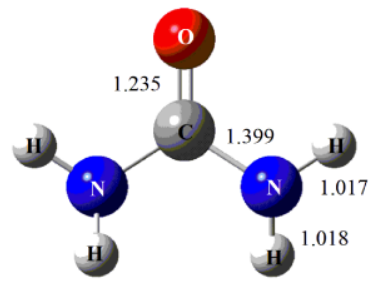

Urea

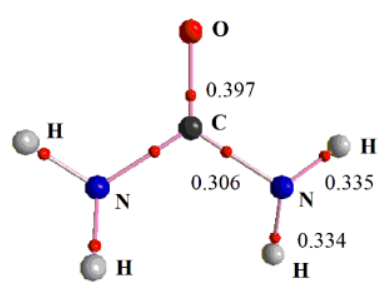

Urea

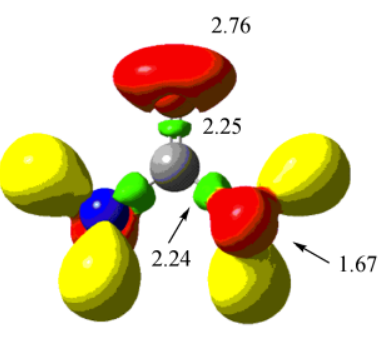

Urea

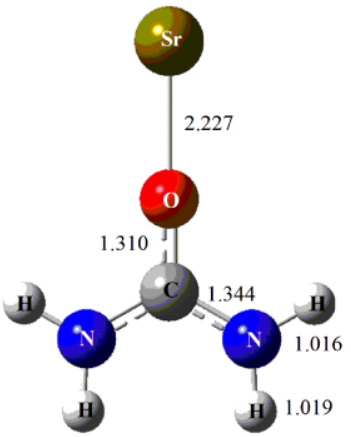

1

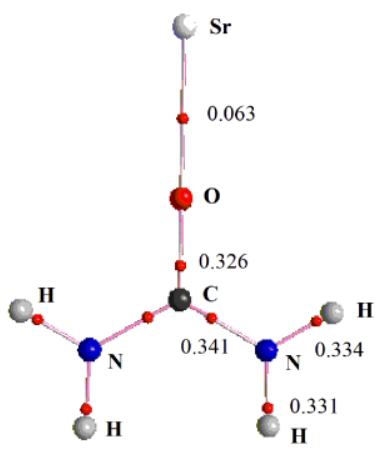

1

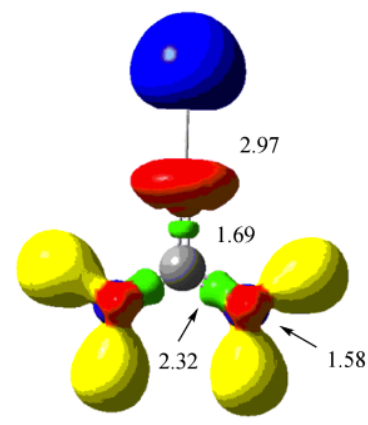

1

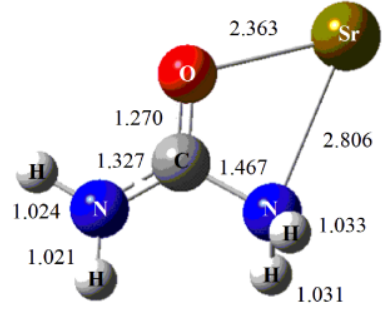

2

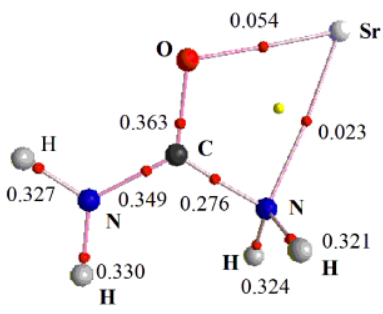

2

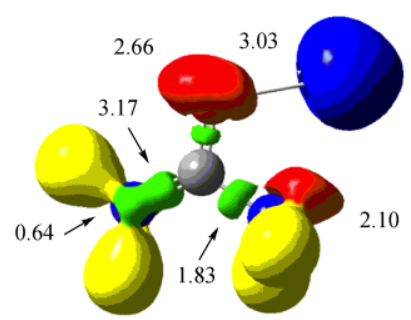

2

Figure 2. Optimized structures, molecular graphs and ELF plots for urea and the most stable urea- $\mathrm{Sr}^{2+}$ adducts. Bond lengths are in $\AA$. The densities at the BCPs (red dots) in the molecular graphs are in a.u.. In the ELF plots, blue, red, green basins correspond to core-pairs, lone-pairs, bonding pairs, respectively. Yellow basins denote disynaptic basins associated with XH bonds. Electron populations are in e.

As it could be anticipated, there is not a significant charge transfer from the base to the metal dication, which in the aforementioned complexes, retains a natural charge close to +2 , consistent with an interaction essentially electrostatic. Coherently, the electron 
density at the $\mathrm{O}-\mathrm{Sr} \mathrm{BCP}$ is rather small, the energy density is positive and there are no disynaptic basins between the metal and the base. However, the strong Coulombic field created by $\mathrm{Sr}^{2+}$ strongly polarizes the electron density distribution of urea, which is clearly reflected in the population of the carbonyl oxygen lone-pairs, which increases from $2.76 \mathrm{e}^{-}$in the isolated base to $2.97 \mathrm{e}^{-}$in complex $\mathbf{1}$, whereas that of the $\mathrm{C}=\mathrm{O}$ disynaptic basin decreases. This activation of the carbonyl bond is also reflected in a decrease of the electron density at the $\mathrm{C}=\mathrm{O} \mathrm{BCP}$ (see Figure 2). The polarization of the electron density towards the metal clearly enhances the conjugation of the amino-groups lone pairs with the $\mathrm{C}=\mathrm{O}$ group. As shown by the ELF of the neutral urea, both lone pairs in the isolated molecule point to opposite sites of the molecular plane, since both groups are significantly pyrimidalized. Conversely, in complex $\mathbf{1}$ the $\mathrm{NH}_{2}$ groups become strictly planar and both lone-pairs point to the same side. The result is a reinforcement of both $\mathrm{C}-\mathrm{N}$ bonds, mirrored in an increase of the population of the $\mathrm{C}-\mathrm{N}$ disynaptic basins and in the electron density at the C-N BCP.

Polarization effects are also apparent in structure 2. Again, the population at the carbonyl oxygen lone-pair interacting with the metal as well as that of the amino group lone pair increases from $2.76 \mathrm{e}^{-}$to $3.03 \mathrm{e}^{-}$and from $1.67 \mathrm{e}^{-}$to $2.10 \mathrm{e}^{-}$, respectively. As a consequence, in this structure, both the $\mathrm{C}-\mathrm{N}$ bond involving the amino group interacting with the metal and the $\mathrm{C}=\mathrm{O}$ bond becomes activated. This activation is quantitatively measured by the decrease of the population of the corresponding disynaptic basins and the decrease in the electron density at the corresponding BCPs (See Figure 2). Also, the existence of two BCPs between $\mathrm{Sr}$ and the $\mathrm{O}$ and $\mathrm{N}$ centers of the base indicates that both centers are strongly polarized, giving rise to a three-membered ring characterized by the corresponding ring critical point. This polarization triggers a better conjugation 
of the amino group not interacting with the metal and the $\mathrm{C}=\mathrm{O}$ group, which results in a planarization of the group and in a reinforcement of the C-N bond.

These bond weakening and bond reinforcement effects are unavoidably mirrored in redand blue shifts respectively of the corresponding stretching vibrational frequencies. Thus, on going from urea to complex $\mathbf{1}$, the $\mathrm{C}=\mathrm{O}$ stretching appears red-shifted by 220 $\mathrm{cm}^{-1}$, whereas the $\mathrm{C}-\mathrm{N}$ stretching, which are coupled as symmetric and antisymmetric combinations appears blue-shifted by 110 and $271 \mathrm{~cm}^{-1}$, respectively.

The calculated binding energy is reasonably high $\left(381 \mathrm{~kJ} \mathrm{~mol}^{-1}\right)$ as it corresponds to a doubly charge metal, but $16 \%$ lower than that estimated for $\mathrm{Ca}^{2+}\left(453 \mathrm{~kJ} \mathrm{~mol}^{-1}\right)^{30}$. This is an expected finding if one takes into account that as mentioned above the interaction of urea with these two metal dications is essentially electrostatic, and the ionic radius of $\mathrm{Ca}^{2+}(114 \mathrm{pm})$ is $14 \%$ smaller than that of $\mathrm{Sr}^{2+}(132 \mathrm{pm})$. It is also worth noting that this binding energy is about $50 \mathrm{~kJ} \mathrm{~mol}^{-1}$ larger than that of formamide, estimated at the same level of theory, clearly reflecting the significant stabilization of the urea-Sr${ }^{2+}$ adduct induced by the conjugation of both amino groups.

\section{Mechanisms for the collision induced dissociation of $[\mathrm{Sr}(\text { urea })]^{2+}$ ions.}

The first point which needs to be addressed is the stability of the $\left[\operatorname{Sr}(\text { urea) }]^{2+}\right.$ adduct, which would be responsible for the experimental peak observed at $m / z 73.96$ in the positive-ion electrospray spectrum. The $\left[\mathrm{Sr}(\text { urea) }]^{2+}\right.$ adduct may undergo, in principle several direct Coulomb explosions, as well as other Coulomb explosions after isomerization. Among the direct Coulomb explosions the following can be envisaged: i) the elimination of the singly-charged metal ion, to yield urea ${ }^{+\cdot}$ (see Figure 3), ii) a deprotonation process leading to the $[\mathrm{Sr}(\text { urea })-\mathrm{H}]^{+}$singly charged species, iii) the 
fragmentation into $[\mathrm{SrO}]^{+}+\left[\mathrm{C}\left(\mathrm{NH}_{2}\right)_{2}\right]^{+}$, iv) to the dissociation into $\left[\mathrm{H}_{2} \mathrm{NSr}\right]^{+}+$ $\left[\mathrm{H}_{2} \mathrm{NCO}\right]^{+}$.

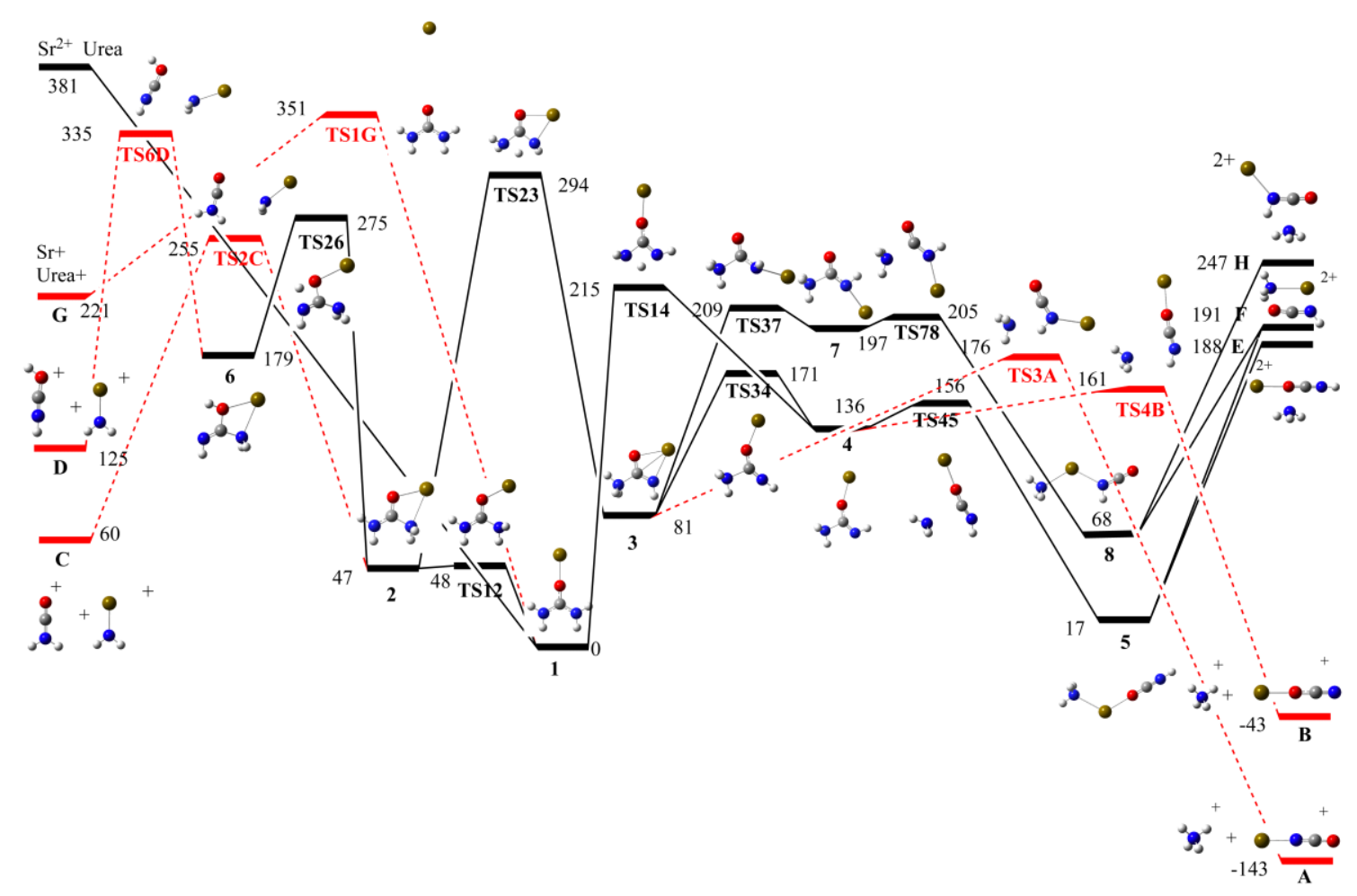

Figure 3. Energy profile corresponding to the $[\operatorname{Sr}(\text { urea })]^{2+}$ unimolecular fragmentation processes. The reaction paths associated with Coulomb explosions are denoted by red dashed lines. All energies in $\mathrm{kJ} \mathrm{mol}^{-1}$

As shown in Figure 3, where we have plotted the energy profile associated with the different unimolecular fragmentations that the $[\operatorname{Sr}(\text { urea })]^{2+}$ complex can undergo, the first Coulomb explosion mentioned above yielding urea ${ }^{+\cdot}$ involves an activation barrier of $351 \mathrm{~kJ} \mathrm{~mol}^{-1}$ and the exit channel is $221 \mathrm{~kJ} \mathrm{~mol}^{-1}$ above the urea- $\mathrm{Sr}^{2+}$ adduct. The deprotonation process (not shown in the figure for the sake of simplicity) is even more endothermic, since the corresponding exit channel is $588.3 \mathrm{~kJ} \mathrm{~mol}^{-1}$ above the global minimum 1, and therefore $207 \mathrm{~kJ} \mathrm{~mol}^{-1}$ above the entrance channel. The explosion yielding $[\mathrm{SrO}]^{+}+\left[\mathrm{C}\left(\mathrm{NH}_{2}\right)_{2}\right]^{+}$(not shown in the figure) is also extremely endothermic, by $311 \mathrm{~kJ} \mathrm{~mol}^{-1}$, with respect to the entrance channel. Also the products $\left[\mathrm{H}_{2} \mathrm{NSr}\right]^{+}+$ 
$\left[\mathrm{H}_{2} \mathrm{NCO}\right]^{+}$corresponding to the last Coulomb explosion lie $60 \mathrm{~kJ} \mathrm{~mol}^{-1}$ above urea-Sr${ }^{2+}$ adduct $\mathbf{1}$. Hence, we can safely conclude that the urea/ $\mathrm{Sr}^{2+}$ doubly charged species are thermodynamically stable with respect to direct Coulomb explosions. However, as we shall discuss later on, they are thermodynamically unstable, although kinetically metastable, with respect to some post-isomerization Coulomb explosions, such as the formation of $\mathrm{NH}_{4}^{+}$.

Taking as starting point the global minimum of the PES, structure 1, that should be the dominant species formed by the interaction of urea and $\mathrm{Sr}^{2+}$ under the experimental conditions used, four different mechanisms can be envisaged: i) the pyramidalization of one of the amino groups leading to the local minimum 2 , ii) the Coulomb explosion

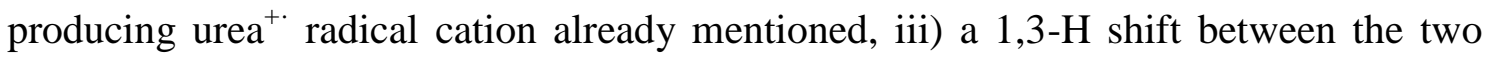
amino groups, which connect the global minimum 1 with the local minimum 4, through the TS14 transition state, iv) a 1,2-H shift from one of the amino groups towards the carbonyl oxygen which, as we shall discuss later on, actually involves isomer 2 leading to minimum 6, through the TS26 transition state.

The most favorable of these four processes is the one connecting $\mathbf{1}$ and $\mathbf{2}$, followed by that leading to local minimum 4. This latter local minimum, in which a $\mathrm{NH}_{3}$ group is attached to the carbonyl carbon atom, is a suitable precursor for the loss of ammonia, which takes place through TS45 and yields a very stable minimum $\mathbf{5}$. Minimum $\mathbf{5}$ plays a crucial role in the $[\operatorname{Sr}(\text { urea })]^{2+}$ fragmentation, since it is a suitable precursor for both the loss of ammonia and the loss of HNCO. As a matter of fact, once minimum $\mathbf{5}$ is formed, there are two alternative mechanisms depending on which of the two bond cleavages, the Sr-N or the Sr-O, are more favorable. Our theoretical estimates show the both process to be practically isoenergetic, within the precision of our theoretical model. This would imply that one should observe with practically equal probability the loss of 
$\mathrm{NH}_{3}$ or the loss of $\mathrm{HNCO}$, corresponding to the peaks at m/z 64.45 and 52.45 in the MS/MS experimental spectra, associated with $[\mathrm{HNCO}-\mathrm{Sr}]^{2+}$ and $\left[\mathrm{H}_{3} \mathrm{~N}-\mathrm{Sr}\right]^{2+}$ doublycharged molecular ions, respectively.

Hence, interestingly some of the fragment ions are new doubly-charged species. In order to gain further insight into their intrinsic stability, we decided to investigate the possible Coulomb explosions they can undergo. Since an accurate estimate of the energies involved might be critical, we decided to explore these processes using CCSD optimized geometries with the expanded basis set B, whereas the final energies were obtained through $\operatorname{CCSD}(\mathrm{T})$ single point calculations with the same basis set. For the $\left[\mathrm{H}_{3} \mathrm{~N}-\mathrm{Sr}\right]^{2+}$ species, two Coulomb explosions can be envisaged, the loss of a proton to yield $\left[\mathrm{H}_{2} \mathrm{~N}-\mathrm{Sr}\right]^{+}$or the fragmentation of the doubly-charged ion into $\mathrm{Sr}^{+}+\mathrm{NH}_{3}^{+}$. However, both processes are estimated to be endothermic with respect to the $\left[\mathrm{H}_{3} \mathrm{~N}-\mathrm{Sr}\right]^{2+}$ doubly-charged species by 579 and $139 \mathrm{~kJ} \mathrm{~mol}^{-1}$, respectively. At the same level of accuracy, the deprotonation of $[\mathrm{HNCO}-\mathrm{Sr}]^{2+}$ was estimated to be extremely endothermic, whereas its dissociation into $\mathrm{Sr}^{+}+\mathrm{HNCO}^{+}$, requires an energetic contribution of $328 \mathrm{~kJ} \mathrm{~mol}^{-1}$. A third possible Coulomb explosion would correspond to its dissociation into $[\mathrm{HNC}]^{+}+[\mathrm{OSr}]^{+}$. However this process is also highly endothermic (by $550 \mathrm{~kJ} \mathrm{~mol}^{-1}$ ). Hence, we can conclude that although the $[\operatorname{Sr}(\text { urea })]^{2+}$ complexes themselves are metastable with respect to the formation of $\mathrm{NH}_{4}{ }^{+}$, their gas-phase collision induced dissociation produce two doubly-charged species, namely [HNCO$\mathrm{Sr}]^{2+}$ and $\left[\mathrm{H}_{3} \mathrm{~N}-\mathrm{Sr}\right]^{2+}$, which are thermodynamically stable.

The other reactive paths have their origin in the less stable adduct $\mathbf{2}$. The most favorable one from the energetic viewpoint is its direct Coulomb explosion through the TS2C activation barrier to $\left[\mathrm{H}_{2} \mathrm{NSr}\right]^{+}+\left[\mathrm{H}_{2} \mathrm{NCO}\right]^{+}$, which correspond indeed to the peaks at $\mathrm{m} / \mathrm{z}$ 103.91 and 44.00 of the MS/MS spectra. Besides, there are two alternative 
isomerization processes through two different $1,3-\mathrm{H}$ shifts, one connecting minimum 2 with minimum $\mathbf{6}$ and another connecting minima $\mathbf{2}$ and $\mathbf{3}$. The one involving a lower barrier is that leading to the local minimum $\mathbf{6}$, which may also undergo a Coulomb explosion yielding again $\left[\mathrm{H}_{2} \mathrm{NSr}\right]^{+}$, the accompanying ion being $[\mathrm{HNCOH}]^{+}$instead of $\mathrm{H}_{2} \mathrm{NCO}^{+}$. This dissociation limit is $65 \mathrm{~kJ} \mathrm{~mol}^{-1}$ above $\left[\mathrm{H}_{2} \mathrm{NSr}\right]^{+}+\left[\mathrm{H}_{2} \mathrm{NCO}\right]^{+}$and at the same time the barrier to reach minimum $\mathbf{6}$ is significantly higher than TS2C, as well as the barrier associated with the Coulomb explosion itself (TS6D). So, we can expect that the only Coulomb explosion producing $\left[\mathrm{H}_{2} \mathrm{NSr}\right]^{+}$is the one with its origin in structure 2 , the partner ion being $\left[\mathrm{H}_{2} \mathrm{NCO}\right]^{+}$.

The second isomerization involving minimum 2 leads to structure 3 . This structure, once formed, may undergo an $\mathrm{NH}$ inversion which results in the cleavage of the $\mathrm{N}-\mathrm{Sr}$ bond yielding structure 4, and from here the processes leading to $\mathrm{E}$ and $\mathrm{F}$ exit channels through the intermediate $\mathbf{5}$ already discussed above will take place. Alternatively, an internal rotation of the SrNH group would connect 3 with 7, which would finally evolve to yield $\mathbf{8}$. The production of complex $\mathbf{8}$ may be followed by two alternative bond cleavages, one leading to the loss of $\mathrm{NH}_{3}$ and the other to the elimination of $\mathrm{NHCO}$, the latter being more favorable by $56 \mathrm{~kJ} \mathrm{~mol}^{-1}$. Note however that the TS23 isomerization barrier is significantly higher than the TS14, so most of the flux should be expected to follow the reactive route through TS14. Hence, the most favorable pathway to reach 7 and 8 should proceed through the isomerization $\mathbf{4} \rightarrow \mathbf{3}$, rather than through the isomerization $\mathbf{2} \rightarrow \mathbf{3}$. Nevertheless, once $\mathbf{3}$ is formed the barriers to reach the two local minima reach $\mathbf{7}$ and $\mathbf{8}$ from $\mathbf{3}$ are much higher in energy than the transition state connecting 4 and $\mathbf{5}$. Hence, the two processes with origin in structure $\mathbf{8}$ should not compete with the similar ones originating from structure 5. This means that the doubly- 
charged ion associated with the loss of ammonia should be expected to be $[\mathrm{HNCOSr}]^{2+}$, rather than $[\mathrm{OCNHSr}]^{2+}$.

Finally, structure $\mathbf{3}$ may also undergo two Coulomb explosions, which are preceded by a Sr-O bond cleavage through the TS3A, or by a Sr-NH bond cleavage through TS3B. As confirmed by the corresponding IRC calculations, the former yields as final products $\left[\mathrm{NH}_{4}\right]^{+}+[\mathrm{OCNSr}]^{+}$, which lies $100 \mathrm{~kJ} \mathrm{~mol}^{-1}$ lower in energy than the $\left[\mathrm{NH}_{4}\right]^{+}+$ $[\mathrm{NCOSr}]^{+}$which are produced in the latter. It is also worth noting that the barriers associated with these two transition states do not change significantly when evaluated at the $\operatorname{CCSD}(\mathrm{T})$ level of theory ( 176 (B3LYP) vs. $176(\mathrm{CCSD}(\mathrm{T})$ and 161(B3LYP) vs. $164(\mathrm{CCSD}(\mathrm{T})) \mathrm{kJ} \mathrm{mol}^{-1}$, respectively) . Experimentally, it is not possible to distinguish one pathway from the other, but according to our calculations, the more exothermic of the two involves an activation barrier higher than the other. Nevertheless, the difference between the two activation barriers is rather small, and therefore we can safely conclude that the monocation which accompanies $\left[\mathrm{NH}_{4}\right]^{+}$would be a mixture of the $[\mathrm{OCNSr}]^{+}$ and $[\mathrm{NCOSr}]^{+}$isomers. Since TS34 is $15 \mathrm{~kJ} \mathrm{~mol}^{-1}$ higher in energy than TS45, one should expect the loss of $\mathrm{NH}_{3}$, by fragmentation of the local minimum $\mathbf{5}$, to be slightly more favorable than the formation of $\mathrm{NH}_{4}{ }^{+}$by the Coulomb explosions of $\mathbf{3}$. This is in a qualitative agreement with the intensities of the corresponding peaks observed in the MS/MS spectra, although, in view of the small difference in the barrier heights, the intensities should not be that different. It should be remembered however that the low experimental intensity measured for $\mathrm{NH}_{4}{ }^{+}$may be due to the discrimination against low mass ions discussed above.

\section{Concluding Remarks}


$[\mathrm{Sr}(\text { Urea })]^{2+}$ adducts are thermodynamically stable with respect to direct Coulomb explosions. However, after isomerization, some of the local minima of the PES are thermodynamically unstable with respect to the formation of $\left[\mathrm{NH}_{4}\right]^{+}$, but kinetically metastable.

As it has been found for the formamide/ $\mathrm{Sr}^{2+}$ system, in urea $/ \mathrm{Sr}^{2+}$ the loss of neutral fragments with concomitant generation of lighter doubly-charged ions, namely $\left[\mathrm{H}_{3} \mathrm{NSr}\right]^{2+}$ and $[\mathrm{HNCOSr}]^{2+}$, compete with the aforementioned Coulomb explosions processes yielding $\left[\mathrm{NH}_{4}\right]^{+}+[\mathrm{NCOSr}]^{+}$and $\left[\mathrm{H}_{2} \mathrm{NSr}\right]^{+}+\left[\mathrm{H}_{2} \mathrm{NCO}\right]^{+}$, although the former processes dominate. Hence, both singly- and doubly-charged species are detected as products of the reaction. Similar reactivity patterns were found for the urea-Ca ${ }^{2+}$ system, with only quantitative differences as far as the height of the activation barriers involved and the relative stabilities of the exit channels.

The two doubly-charged species, namely $\left[\mathrm{H}_{3} \mathrm{NSr}\right]^{2+}$ and $[\mathrm{HNCOSr}]^{2+}$, produced by the loss of HNCO and ammonia, respectively, turn out to be thermodynamically stable.

\section{References}

(1) Ausloos, P. J. Ion-Molecule Reactions in the Gas Phase; American Chemical Society: New York, 1967; Vol. 58.

(2) Nibbering, N. M. M. Gas-Phase Ion Molecule Reactions as Studied by Fourier-Transform Ion-Cyclotron Resonance Accounts Chem. Res. 1990, 23, 279-285.

(3) Nibbering, N. M. M. Four Decades of Joy in Mass Spectrometry.Mass Spectrom. Rev. 2006, 25, 962-1017.

(4) Cooks, R. G.; Patrick, J. S.; Kotiaho, T.; McLuckey, S. A. Thermochemical Determinations by the Kinetic Method.Mass Spectrom. Rev. 1994, 13, 287-339.

(5) Born, M.; Ingemann, S.; Nibbering, N. M. M. Formation and Chemistry of Radical Anions in the Gas Phase.Mass Spectrom. Rev. 1997, 16, 181-200.

(6) Brodbelt, J. S. Analytical Applications of Ion-Molecule Reactions.Mass Spectrom. Rev. 1997, 16, 91-110.

(7) Green, M. K.; Lebrilla, C. B. Ion-Molecule Reactions as Probes of GasPhase Structures of Peptides and Proteins.Mass Spectrom. Rev. 1997, 16, 53-71. 
(8) Zenobi, R.; Knochenmuss, R. Ion Formation in MALDI Mass Spectrometry.Mass Spectrom. Rev. 1998, 17, 337-366.

(9) Fujii, T. Alkali-Metal Ion/Molecule Association Reactions and their Applications to Mass Spectrometry.Mass Spectrom. Rev. 2000, 19, 111-138.

(10) Operti, L.; Rabezzana, R. Gas-Phase Ion Chemistry in Organometallic Systems.Mass Spectrom. Rev. 2006, 25, 483-513.

(11) Lamsabhi, A. M.; Yáñez, M.; Salpin, J. Y.; Tortajada, J. Gas-Phase Chemistry of Organocopper Compounds. In The Chemistry of organocopper compounds; Rappoport, Z., Marek, I., Eds.; J.Wiley \&Sons: London, 2009; Vol. 279346.

(12) Schröder, D.; Schwarz, H. Generation, Stability, and Reactivity of Small, Multiply Charged Ions in the Gas Phase.J. Phys. Chem. A 1999, 103, 7385-7394.

(13) Blades, A. T.; Jayaweera, P.; Ikonomou, M. G.; Kebarle, P. Ion-Molecule Clusters Involving Doubly Charged Metal-Ions (M2+).Int. J. Mass Spectrom. Ion Process. 1990, 102, 251-267.

(14) Blades, A. T.; Jayaweera, P.; Ikonomou, M. G.; Kebarle, P. Studies of Alkaline-Earth and Transition-Metal M++ Gas-Phase Ion Chemistry.J. Chem. Phys. 1990, 92, 5900-5906.

(15) Jayaweera, P.; Blades, A. T.; Ikonomou, M. G.; Kebarle, P. Production and Study in the Gas-Phase of Multiply Charged Solvated or Coordinated Metal-Ions.J. Am. Chem. Soc. 1990, 112, 2452-2454.

(16) El-Nahas, A. M. On the Existence of $\mathrm{Cu}^{2+}\left(\mathrm{NH}_{3}\right)_{1,2}$ and $\mathrm{Cu}^{2+}(\mathrm{OH} 2)_{1,2}$ in the Gas Phase.Chem. Phys. Lett. 2000, 329, 176-178.

(17) Stace, A. J.; Walker, N. R.; Wright, R. R.; Firth, S. Comment on "Do $\mathrm{Cu} 2+\mathrm{NH} 3$ and $\mathrm{Cu} 2+\mathrm{H} 2 \mathrm{O}$ Exist?: Theory Confirms Yes!" (Chemical Physics Letters 318 (2000) 333-339).Chem. Phys. Lett. 2000, 329, 173-175.

(18) Schroder, D. S.; Schwarz, H.; Wu, J.; Wesdemiotis, C. Long-Lived Dications of $\mathrm{Cu}\left(\mathrm{H}_{2} \mathrm{O}\right)^{2+}$ and $\mathrm{Cu}\left(\mathrm{NH}_{3}\right)^{2+}$ Do Exist!Chem. Phys. Lett. 2001, 343, 258264.

(19) Palacios, A.; Corral, I.; Mó, O.; Martín, F.; Yáñez, M. On the Existence and Lifetimes of $\mathrm{Cu} 2+$ Complexes with Water, Ammonia and Hydrogen Cyanide.J. Chem. Phys. 2005, 123, 014315 (014311-014315).

(20) Bertrán, J.; Rodríguez-Santiago, L.; Sodupe, M. The Different Nature of Bonding in $\mathrm{Cu}^{+}$-Glycine and $\mathrm{Cu}^{2+}$-Glycine.J. Phys. Chem. B 1999, 103, 2310-2317.

(21) Noguera, M.; Bertran, J.; Sodupe, M. A Quantum Chemical Study of $\mathrm{Cu}^{2+}$ Interacting with Guanine-Cytosine Base Pair. Electrostatic and Oxidative Effects on Intermolecular Proton-TransferProcesses.J. Phys. Chem. A 2004, 108, 333-341.

(22) Lamsabhi, A. M.; Alcamí, M.; Mó, O.; Yáñez, M.; Tortajada, J. GasPhase Deprotonation of Uracil-Cu2+ and Thiouracil-Cu2+Complexes.J. Phys. Chem. A 2006, 110, 1943-1950.

(23) Trujillo, C.; Lamsabhi, A. M.; Mó, O.; Yáñez, M. The Importance of the Oxidative Character of Doubly Charged Metal Cations in Binding Neutral Bases. [Urea$\mathrm{M}](2+)$ and [Thiourea-M] $(2+)(\mathrm{M}=\mathrm{Mg}, \mathrm{Ca}, \mathrm{Cu})$ Complexes.Phys. Chem. Chem. Phys. 2008, 10, 3229-3235.

(24) Lamsabhi, A. M.; Alcamí, M.; Mó, O.; Yáñez, M.; Tortajada, J.; Salpin, J. Y. Unimolecular Reactivity of Uracil- $\mathrm{Cu}^{2+}$ Complexes in the Gas Phase.ChemPhysChem 2007, 8, 181-187.

(25) Reiter, A.; Zhao, H.; Adams, J. Intrinsic Specificity of Ca2+ ProteinBinding Sites.Org. Mass Spectrom. 1993, 28, 1596-1601. 
(26) Dobson, M. P.; Stace, A. J. The Chemistry of Sr2+ in Association with Propanol Clusters.Int. J. Mass Spectrom. 1997, 165, 5-12.

(27) Lavanant, H.; Hecquet, E.; Hoppilliard, Y. Complexes of L-Histidine with $\mathrm{Fe} 2+, \mathrm{Co} 2+, \mathrm{Ni} 2+, \mathrm{Cu} 2+, \mathrm{Zn} 2+$ Studied by Electrospray Ionization Mass Spectrometry.Int. J. Mass Spectrom. 1999, 185, 11-23.

(28) Rodriguez-Cruz, S. E.; Williams, E. R. Gas-Phase Reactions of Hydrated Alkaline Earth Metal Ions, $\mathrm{M}^{2+}\left(\mathrm{H}_{2} \mathrm{O}\right)(\mathrm{n})(\mathrm{M}=\mathrm{Mg}, \mathrm{Ca}, \mathrm{Sr}, \mathrm{Ba}$ and $\mathrm{n}=4-7)$, with Benzene.J. Am. Soc. Mass Spectrom. 2001, 12, 250-257.

(29) Bienkowski, T.; Brodzik-Bienkowska, A.; Danikiewicz, W. Complexes of Bivalent Metal Cations in Electrospray Mass Spectra of Common Organic Compounds.J. Mass Spectrom. 2002, 37, 617-622.

(30) Corral, I.; Mó, O.; Yáñez, M.; Salpin, J. Y.; Tortajada, J.; Radom, L. Gas-phase Reactions Between Urea and $\mathrm{Ca}^{2+}$ : The Importance of Coulomb Explosions.J. Phys. Chem. A 2004, 108, 10080-10088.

(31) Fung, Y. M. E.; Liu, H. C.; Chan, T. W. D. Electron Capture Dissociation of Peptides Metalated with Alkaline-Earth Metal Ions.J. Am. Soc. Mass Spectrom. 2006, 17, 757-771.

(32) Plane, J. M. C.; Vondrak, T.; Broadley, S.; Cosic, B.; Ermoline, A.; Fontijn, A. Kinetic Study of the Reaction $\mathrm{Ca}^{+}+\mathrm{N}_{2} \mathrm{O}$ from 188 to 1207 K.J. Phys. Chem. A 2006, 110, 7874-7881.

(33) Corral, I.; Mó, O.; Yáñez, M.; Salpin, J. Y.; Tortajada, J.; Moran, D.; Radom, L. An Experimental and Theoretical Investigation of Gas-Phase Reactions of Ca2+ with Glycine.Chem.-Eur. J. 2006, 12, 6787-6796.

(34) Feil, S.; Koyanagi, G. K.; Viggiano, A. A.; Bohme, D. K. Ozone Reactions with Alkaline-Earth Metal Cations and Dications in the Gas Phase: RoomTemperature Kinetics and Catalysis.J. Phys. Chem. A 2007, 111, 13397-13402.

(35) Shi, T. J.; Hopkinson, A. C.; Siu, K. W. M. Coordination of Triply Charged Lanthanum in the Gas Phase: Theory and Experiment.Chem.-Eur. J. 2007, 13, 1142-1151.

(36) Trujillo, C.; Mó, O.; Yáñez, M.; Salpin, J. Y.; Tortajada, J. Gas-phase Reactions Between Thiourea and $\mathrm{Ca}^{2+}$ : New Evidence for the Formation of $\left[\mathrm{Ca}\left(\mathrm{NH}_{3}\right)\right]^{2+}$ and Other Doubly Charged Species.ChemPhysChem 2007, 8, 1330-1337.

(37) Jobst, K. J.; Terlouw, J. K.; Luider, T. M.; Burgers, P. C. On the Interaction of Peptides with Calcium Ions as Studied by Matrix-Assisted Laser Desorption/ionization Fourier Transform Mass Spectrometry: Towards Peptide Fishing Using Metal Ion Baits.Anal. Chim. Acta 2008, 627, 136-147.

(38) Trujillo, C.; Mó, O.; Yáñez, M.; Tortajada, J.; Salpin, J. Y. Selenourea$\mathrm{Ca} 2+$ Reactions in Gas Phase. Similarities and Dissimilarities with Urea and Thiourea.J. Phys. Chem. B 2008, 112, 5479-5486.

(39) Eizaguirre, A.; Mó, O.; Yáñez, M.; Salpin, J. Y. Modeling the Interactions Between Peptide Functions and Sr2+: Formamide-Sr2+ Reactions in the Gas Phase.Phys. Chem. Chem. Phys. 2011, 13, 18409-18417.

(40) Spezia, R.; Cimas, A.; Gaigeot, M. P.; Salpin, J. Y.; Song, K.; Hase, W. L. Collision Induced Dissociation of Doubly-Charged Ions: Coulomb Explosion vs. Neutral Loss in $[\mathrm{Ca}(\text { Urea })]^{2+}$ Gas Phase Unimolecular Reactivity via Chemical Dynamics Simulations.Phys. Chem. Chem. Phys. 2012, 14, 11724-11736.

(41) Cimas, A.; Gamez, J. A.; Mó, O.; Yáñez, M.; Salpin, J. Y. Computational Study on the Kinetics of the Reaction Between $\mathrm{Ca}^{2+}$ and Urea.Chem. Phys. Lett. 2008, 456, 156-161. 
(42) Meunier, P. J.; Roux, C.; Ortolani, S.; Badurski, J.; Kaufman, J. M.; Spector, T.; Diez-Perez, A.; Seeman, E.; Lemmel, E.; Balogh, A.et al. Strontium Ranelate Reduces the Vertebral Fracture Risk in Women with Postmenopausal Osteoporosis.Osteoporosis Int. 2002, 13, 521-522.

(43) Meunier, P. J. Strontium Ranelate in theTreatment of Postmenopausal Osteoporosis.J. Bone Miner. Res. 2004, 19, 1029-1029.

(44) Chernushevich, I. V.; Loboda, A. V.; Thomson, B. A. An introduction to quadrupole-time-of-flight mass spectrometry.J. Mass Spectrom. 2001, 36, 849-865.

(45) Eizaguirre, A.; Yáñez, M.; Tortajada, J.; Salpin, J.-Y. Sr ${ }^{2+}$-Neutral Molecules Interactions. An Assessment of Theoretical Procedure.Chem. Phys. Lett. 2008, 464, 240-244.

(46) Gill, P. M. W. A New Gradient-Corrected Exchange Functional.Mol. Phys. 1996, 89, 433-445.

(47) Lee, C.; Yang, W.; Parr, R. G. Development of the Colle-Salvetti Correlation-Energy Formula into a Functional of the Electron Density.Phys. Rev. B 1988, 37, 785-789.

(48) Palacios, A.; Martín, F.; Mó, O.; Yáñez, M.; Maksic, Z. B. Stable Doubly Charged Positive Ions Formed by Direct Attachment of Alpha Particles to HCN and HNC.Phys. Rev. Lett. 2004, 92, 133001.

(49) Corral, I.; Palacios, A.; Yáñez, M. On the Stability and Lifetime of $\mathrm{GaO}^{2+}$ in the Gas Phase.Theor. Chem. Acc. 2011, 129, 401-407.

(50) Corral, I.; Yáñez, M. $\left[\mathrm{ML}_{\mathrm{n}}\right]^{2+}$ Doubly Charged Systems: Modeling, Bonding, Life Times and Unimolecular Reactivity.Phys. Chem. Chem. Phys. 2011, 13, 14848-14864.

(51) Corral, I.; Palacios, A.; Yáñez, M. Electronic Structure and Lifetimes of $\mathrm{GaX}^{2+}(\mathrm{X}=\mathrm{N}, \mathrm{O}, \mathrm{F})$ in the Gas Phase. Unraveling Stability Trends.Phys. Chem. Chem. Phys. 2011, 13, 18365-18372.

(52) Matta, C. F.; Boyd, R. J. The Quantum Theory of Atoms in Molecules; Wiley-VCH: Weinheim, 2007.

(53) Bader, R. F. W. Atoms in Molecules. A Quantum Theory; Clarendon Press: Oxford, 1990.

(54) AIMAll (Version 11.12.19); Keith, T. A., Ed.; TK Gristmill Software: Overland Park KS, USA, 2011.

(55) Becke, A. D.; Edgecombe, K. E. A Simple Measure of Electron Localization in Atomic and Molecular Systems.J. Chem. Phys. 1990, 92, 5397-5403.

(56) Silvi, B.; Savin, A. Classification of Chemical-Bonds Based on Topological Analysis of Electron Localization Functions.Nature 1994, 371, 683-686.

(57) Mó, O.; Yáñez, M.; Martín Pendás, A.; Del Bene, J. E.; Alkorta, I.; Elguero, J. Unusual Substituent Effects on the Bonding of Iminoboranes.Phys. Chem. Chem. Phys. 2007, 9, 3970-3977.

(58) Noury, S.; Krokidis, X.; Fuster, F.; Silvi, B. Computational Tools for the Electron Localization Function Topological Analysis.Comput. Chem. 1999, 23, 597604.

(59) Trujillo, C.; Lamsabhi, A.; Mó, O.; Yáñez, M.; Salpin, J. Y. Unimolecular Reactivity upon Collision of Uracil-Ca(2+) Complexes in the Gas Phase: Comparison with Uracil-M(+) $(\mathrm{M}=\mathrm{H}$, Alkali Metals $)$ and Uracil- $\mathrm{M}(2+)(\mathrm{M}=\mathrm{Cu}, \mathrm{Pb})$ Systems.Int. J. Mass Spectrom. 2011, 306, 27-36.

(60) Eizaguirre, A.; Mó, O.; Yáñez, M.; Salpin, J.-Y.; Tortajada, J. Modelling Peptide-Metal Dication Interactions: Formamide-Ca2+ Reactions in the Gas Phase.Org. Biomol. Chem. 2012, 10, 7552-7561. 
(61) Kohler, M.; Leary, J. A. Gas Phase Reactions of Doubly Charged Alkaline Earth and Transition Metal(II)-Ligand Complexes Generated by Electrospray Ionization.Int. J. Mass Spectrom. Ion Process. 1997, 162, 17-34.

(62) Kohler, M.; Leary, J. A. Gas-Phase Reactions of Doubly Charged Alkaline Earth and Transition Metal Complexes of Acetonitrile, Pyridine, and Methanol Generated by ElectrosprayIonization.J. Am. Soc. Mass Spectrom. 1997, 8, 1124-1133.

(63) Kohno, J.; Mafune, F.; Kondow, T. Cluster Ion Formation from Alcohol Solutions of $\mathrm{CaI}_{2} . J$. Phys. Chem. A 1999, 103, 1518-1522.

(64) Luna, A.; Amekraz, B.; Morizur, J. P.; Tortajada, J.; Mó, O.; Yáñez, M. Reactions of Urea with $\mathrm{Cu}^{+}$in the Gas Phase: An Experimental and Theoretical study.J. Phys. Chem. A 2000, 104, 3132-3141.

(65) Schröder, D.; Weiske, T.; Schwarz, H. Dissociation Behavior of $\mathrm{Cu}(\mathrm{Urea})^{(+)}$Complexes Generated by Electrospray Ionization.Int. J. Mass Spectrom. 2002, 219, 729-738.

(66) Rodriguez-Santiago, L.; Noguera, M.; Sodupe, M.; Salpin, J. Y.;

Tortajada, J. Gas Phase Reactivity of $\mathrm{Ni}^{+}$with Urea. Mass Spectrometry and Theoretical Studies.J. Phys. Chem. A 2003, 107, 9865-9874. 